\title{
Generate Reservoir Depths Mapping by Using Digital Elevation Model: A Case Study of Mosul Dam Lake, Northern Iraq
}

\author{
Mohammed F. O. Khattab ${ }^{1,2 *}$, Rudy K. Abo' ${ }^{1}$, Sameh W. Al-Muqdadi' ${ }^{1}$, Broder J. Merkel ${ }^{1}$ \\ ${ }^{1}$ Faculty of Geoscience and Geo-Engineering and Mining, TU Bergakademie Freiberg, Freiberg, Germany \\ ${ }^{2}$ Remote Sensing Center, Mosul University, Mosul, Iraq \\ Email: *mohummedz2004@yahoo.com
}

How to cite this paper: Khattab, M.F.O., Abo, R.K., Al-Muqdadi, S.W. and Merkel, B.J. (2017) Generate Reservoir Depths Mapping by Using Digital Elevation Model: A Case Study of Mosul Dam Lake, Northern Iraq. Advances in Remote Sensing, 6, 161174 .

https://doi.org/10.4236/ars.2017.63012

Received: May 22, 2017

Accepted: August 13, 2017

Published: August 16, 2017

Copyright $\odot 2017$ by authors and Scientific Research Publishing Inc. This work is licensed under the Creative Commons Attribution International License (CC BY 4.0).

http://creativecommons.org/licenses/by/4.0/

cC) (i) Open Access

\begin{abstract}
Not many bathymetric maps are available for many lakes and reservoirs in developing countries. Usually the bathymetric mapping requires investment in expensive equipment and fieldwork, both of which are not accessible in these countries. This work demonstrates the ability to develop bathymetric map of Mosul Lake by using a digital elevation model (DEM). The depths model of the lake was designed through the use of three main stages; a coastline extraction, dataset interpolation and a triangular irregular network model. The normalized difference water index (NDWI) was used for automatic delineation of the lake coastline from satellite images. The ordinary kriging interpolation with a stable model was used to interpolate the water depths dataset. Finally a triangulated irregular network (TIN) model was used to visualize the resulting interpolation model. Calculated values of area and volume of a TIN model during 2011 were compared with values of supposed initial operation of the reservoir. The differences of water volume storage between these stages at $321 \mathrm{~m}$ water level was about $0.81 \times 10^{9} \mathrm{~m}^{3}$, where the lake lost around $10 \%$ of storage value. Also the results of depths lake model show that the change in water storage between March and July 2011 was about $3.08 \times 10^{9} \mathrm{~m}^{3}$.
\end{abstract}

\section{Keywords}

Water Depth, DEM, Bathymetry Map, Mosul Lake

\section{Introduction}

Bathymetric information is essential for understanding the ecosystem of a lake [1]. The characteristics of the lake basin morphology have an important influ- 
ence on the interactions between biological, chemical and physical properties of aquatic environments [2]. Furthermore, ignorance of lake depth leads to quantitative errors in the evaluation of general transport processes such as sedimentation, resuspension, diffusion, mixing, burial and outflow [3]. Therefore, the bathymetry of the lake's bottom directly impacts many water quality parameters such as thermal properties, internal phosphorus recycling, water clarity, suspended particulate matter and many chemical variables [2] [3]. The bottom morphology of a lake can be greatly influenced by deposition of sediment carried by inflowing rivers and streams. Although this process can be modified by wave and current action [4].

Despite the importance of Bathymetric surveys for lakes and reservoirs, most developing countries face obstacles in this field. The cost of surveying equipment and the location of these reservoirs within unsafe regions are the biggest obstacles. The main objective of this study was to build a 3D model for the Mosul Lake bathymetric base from digital elevation data. Remote sensing data had been used to map the Mosul Lake coastline during the period of study, March and July 2011. Furthermore, a set of ordinary kriging models were tested to select the best simulation for the bathymetric dataset. The calculated values of selected bathymetric models were compared with observed field survey data to check the accuracy and observe the developing of the lake bottom during the time of reservoir operation. A 3D TIN model of Mosul Lake was designed to support decision-makers with managing the reservoir. Furthermore, models are an effective tool to understand changes in the lake environment regarding the impact of changing seasonal water storage volume.

\section{Description of Study Area}

First, confirm that you have the Mosul Dam Lake is an artificial reservoir located between latitude $\left(36^{\circ} 36^{\prime} \mathrm{N}-36^{\circ} 50^{\prime} \mathrm{N}\right)$ and longitude $\left(42^{\circ} 27^{\prime} \mathrm{E}-42^{\circ} 58^{\prime} \mathrm{E}\right)$ on the Tigris River about $60 \mathrm{~km}$ north of Mosul City and $80 \mathrm{~km}$ from the borders of Syria and Turkey Figure 1. The surface area of the lake is about $385 \mathrm{~km}^{2}$; the length is about $45 \mathrm{~km}$ and the width ranges between 2 and $14 \mathrm{~km}$ at the maximum operation level (330 meters above sea level) with a maximum storage volume of $11.11 \times 10^{9} \mathrm{~m}^{3}$ and a maximum water depth of $80 \mathrm{~m}$. Its drainage basin covers $4200 \mathrm{~km}^{2}$ inside Iraq [5] [6] [7]. The majority of the water entering the lake comes from Turkey. The mean annual discharge of the Tigris River was in the range from 270 to $1371 \mathrm{~m}^{3} / \mathrm{s}$ for the period from 1931 to 1997 at Mosul station [8]. Usually, the highest monthly discharge occurs during April and May and there is less discharge in October and September.

\section{Methodology}

In the current study, remote sensing data were used to automatic waterline extraction for Mosul Dam Lake. A bathymetric model of the lake was constructed from a $30 \mathrm{~m}$ SRTM dataset. Field data survey and topographic maps were used 


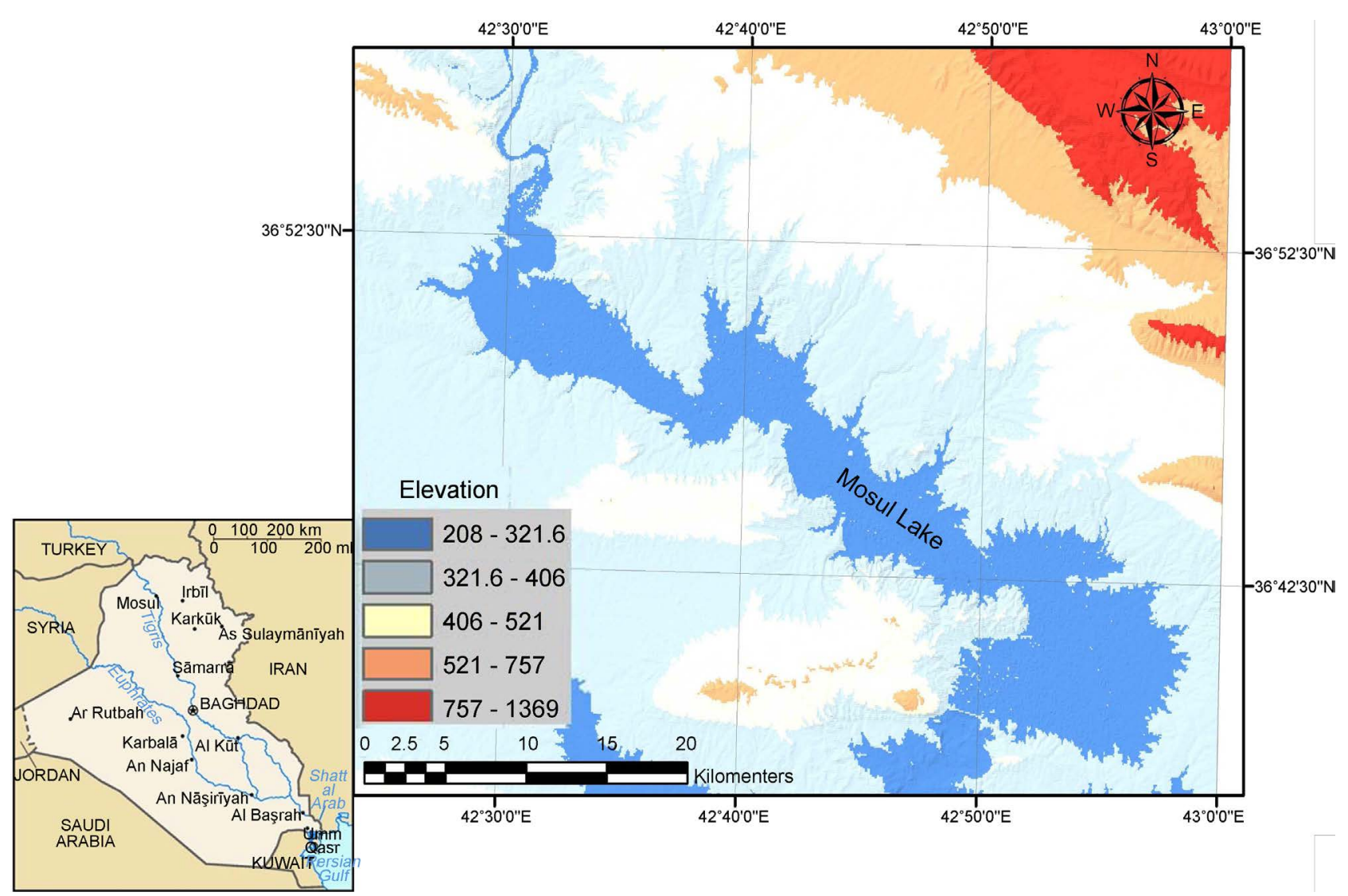

Figure 1. Location map of study area.

to verification and correction the model. The exact locations of the measurements were determined using a Garmin eTrex Legend Cx GPS.

\subsection{Data Bathymetric Collection}

The dataset of the Mosul Dam Lake bathymetry model analysis included 6424 geo-referenced elevation points. These points derive from, a $30 \mathrm{~m}$ SRTM dataset of Iraq was supplied by the U.S Army. The topographical maps were obtained from the Military Survey Office before and after the dam construction at a scale of 1:100,000 were used to check and correction the values of Mosul waterline lake. Finally, the field water depth points were measured with the Water Quality Probe (YSI 6600 V2) and standard field survey equipment used to verification the model. During field work, the elevation of the lake's surface measured in March was 307 m.a.s.l, and in July it was almost 322 m.a.s.l. A Garmin (etrex) GPS was used to fix the geographical coordinates of field water depth points.

\subsection{Coastline Extraction}

A coastline is a line separating land and water mass. It is a ground feature used to obtain the orientation and shape of land and water [9] [10]. Optical remote sensing data can be used to detect the shoreline using either digitization or ratio images [11]. In the current study, the normalized difference water index 
(NDWI) was used for automatic delineation of the coastline of Mosul Dam Lake from satellite images. TM5 and ETM+ images downloaded from the US Geological Survey (USGS) database (http://glovis.usgs.gov/) were used to capture the waterline of Mosul Lake. The Landsat program as an L1T product is used to catalogue the images, which are georeferenced with a level of precision exceeding 0.44 pixels (meaning $13.4 \mathrm{~m}$ ) [12] [13] [14]. ETM+ and TM5 images were captured in March and July 2011, consequently. The images were picked up simultaneously with the operation of water quality sampling. More details on image attributes, enhancement and correction are provided by Khattab and Merkel (2014) [12].

In the current study, the NDWI used for TM5 and ETM+ images was as follows [15] [16]:

$$
\begin{aligned}
& \mathrm{NDVI}_{\mathrm{ETM}+}=(\rho N I R-\rho S W I R) /(\rho N I R+\rho S W I R) \\
& \mathrm{NDWI}_{\mathrm{TM} 5}=(\rho \text { Green }-\rho N I R) /(\rho \text { Green }+\rho N I R)
\end{aligned}
$$

where $\rho N I R, \rho S W I R$, and $\rho$ Green are the reflectance of the near-infrared band (band 4), the short-wave infrared (band 5), and the green band (band 2), respectively.

The results of waterline extraction for Mosul Dam Lake between March 5, 2011 and July 3, 2011 are shown in Figure 2. The surface area of the lake was $142 \mathrm{~km}^{2}$ during March and $285 \mathrm{~km}^{2}$ during July, and the difference in the surface area of the lake during the two periods was more than $33 \%$.

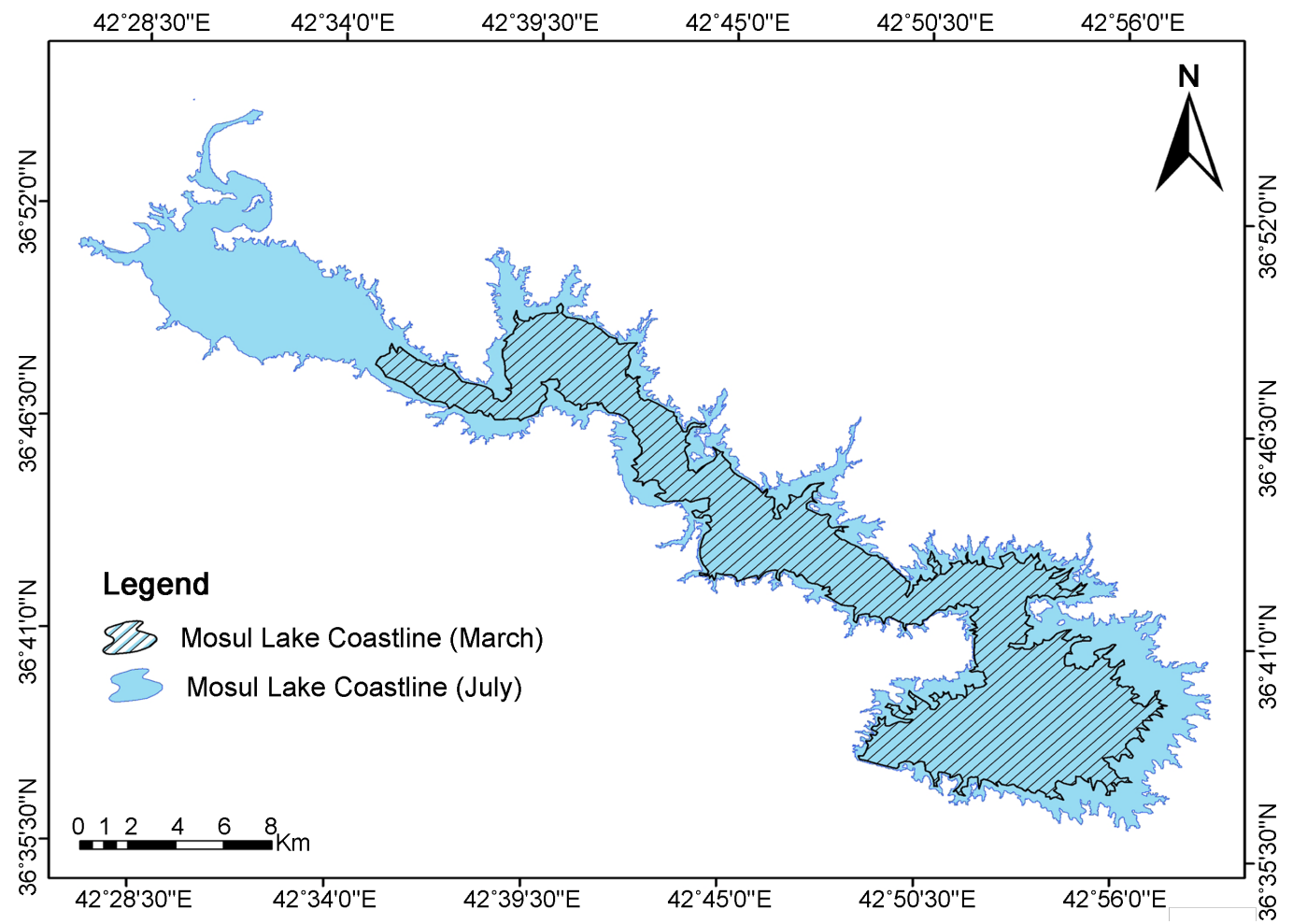

Figure 2. Coastline of Mosul Dam Lake during March and July 2011. 


\subsection{Interpolation Technique}

After pre-processing of the elevation and depth dataset (geographical position union and calibration between DEM and topographical map data points), these points values were merged into a database with 6424 points. The kriging or co-kriging interpolation method was used to build a digital terrain model of Mosul Lake's bathymetry. This method is a powerful geostatistical interpolation technique based on the spatial correlation of sampled points [17] [18]. The predictive values are derived by using weighted averages of known input point values [19] [20]. Kriging to estimate the depth at a spatial point weight $Z(u)$ defined as a linear regression estimator was recorded as below [21].

$$
Z(u)-m(u)=\sum_{a=1}^{n(u)} \lambda\left[Z\left(u_{a}\right)-m\left(u_{a}\right)\right]
$$

where $u$ and $u_{\alpha}$ are spatial locations of an observation point and one of the neighboring data points, indexed by $\alpha, n(u)$ is the number of data points in the local neighborhood used for estimation, $m(u)$ and $m\left(u_{\alpha}\right)$ are the expected values (means) of $Z(u)$ and $Z\left(u_{\alpha}\right)$, and $\lambda_{\alpha}(u)$ is the kriging weight assigned to datum $Z\left(u_{a}\right)$ for estimation location $u$. In the current study, ordinary kriging type was selected to interpolate the bathymetry dataset, where this method gives the best statistical results. [19]. Ordinary kriging is a linear weighted-average technique which is unbiased with regard to the expected value of residuals [22]. In this context, we assume that the mean is constant in the local neighborhood of each estimation point and $m(u)=m\left(u_{\alpha}\right)$ for each nearby data value and $Z\left(u_{\alpha}\right)$ is used to estimate $Z(u)$ [23]. Hence, the kriging estimator can be written as [24].

$$
Z_{o k}^{*}(u)=\sum_{\alpha=1}^{n(u)} \lambda_{a}^{o k} a(u) Z\left(u_{a}\right) \text { with } \sum_{\alpha=1}^{n(u)} \lambda_{a}^{o k}(u)=1
$$

These previous complex geospatial equations were applied in ArcGIS. The geostatistical analysis option in ArcGIS was used to interpolate the dataset of Mosul Lake's bathymetry.

\subsection{Volume Calculation}

There are various techniques for 3D visualizing data on digital terrain models. The regular grid surface (grid) and TIN are among the more well-known techniques [25]. TIN formulas have been used successfully to visualize non-homogeneous surfaces [25]. Hence, TIN models are used for the accurate control of the terrain slope, aspect, surface areas, volumetric and cut/fill analysis, and for generating contour lines [26] [27]. A TIN is a vector terrain model using Delaunay triangles to join points in the three-dimensional space [28]. In the model, all the triangles for a set of points have a circumscribing circle without other vertices [29]. This method provides a set of unique vertices and allows repetition of the calculations and validation of the results separately [30]. This spatial distribution of triangles is the best to reflect the relief of the surface [25]. For the study area, triangles were created between the non-uniform bathymetric mapping data points of the lake (Figure 3). 


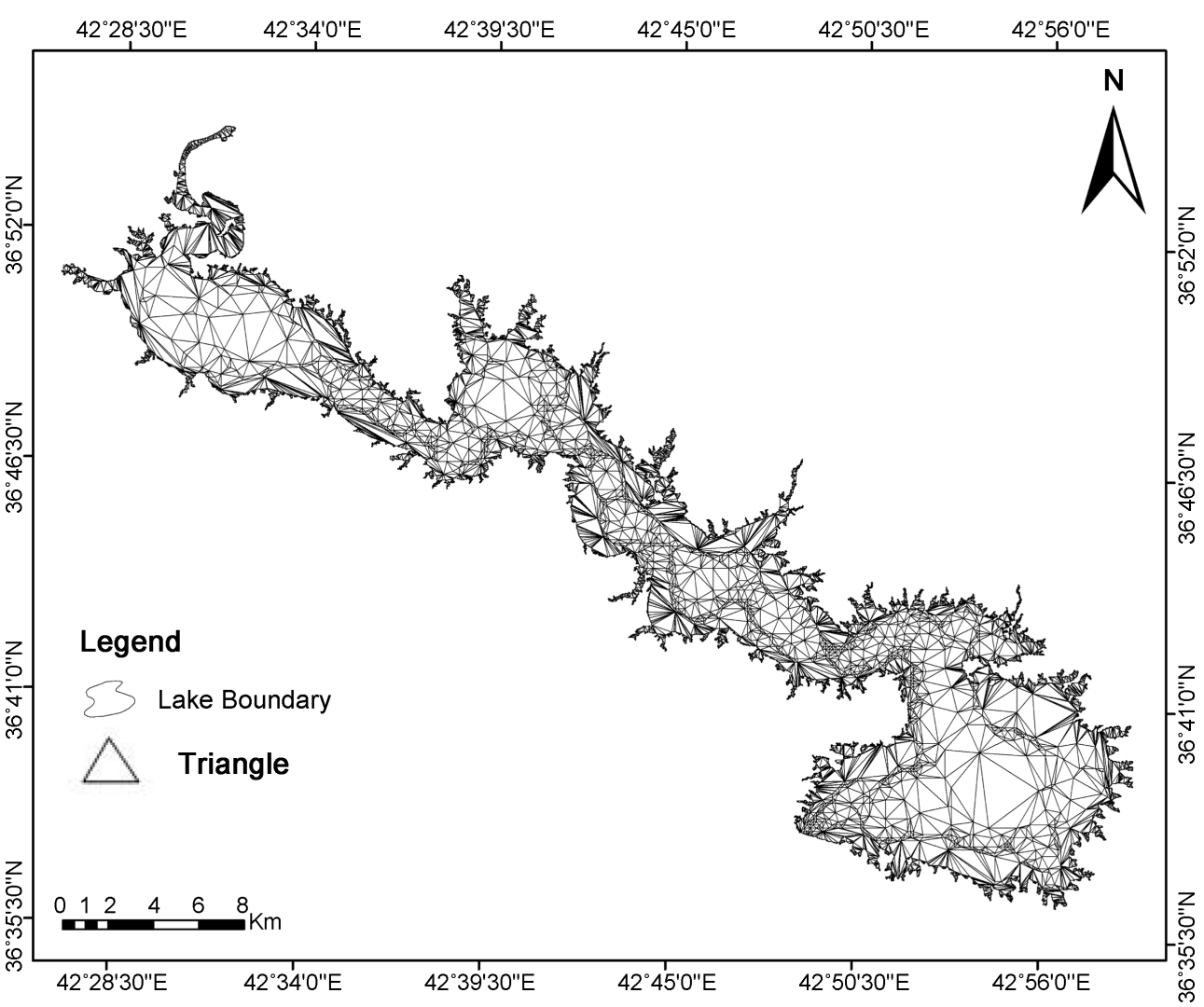

Figure 3. Subdivision of the lake into Delaunay triangles using the TIN approach for generating a digital bathymetric model of the study area.

\section{Results and Discussion}

\subsection{Bathymetric Mapping Analysis}

The ordinary kriging (co-kriging) interpolation method was used to assign depth values to 84,838 geo-referenced points (Figure 4). Root mean square error (RMSE), mean standardized error (MSE), mean error (ME) and average standard error (ASE) were calculated to check the performance of the ordinary kriging models (Table 1). The calculated errors served for comparing the ordinary kriging interpolation models. Generally, RMSE is used to indicate how closely the values predicted by the model are to the measured values, MSE is used to estimate the uncertainty in predicting a population mean, and ASE is used to evaluate the accuracy of the prediction model's average values. ME is used for determining the degree of bias in the estimates [17] [31] [32]. The different errors are calculated as follows:

$$
\begin{gathered}
\mathrm{RMSE}=\sqrt{\frac{1}{n} \sum_{i=1}^{n}\left(Z_{i}-Z_{i}^{\prime}\right)^{2}} \\
\mathrm{MSE}=\frac{\sum_{i=1}^{n}(Z(S i)-z(S i)) / \sigma(S i)}{n} \\
\mathrm{ASE}=\sqrt{\frac{\sum_{i=1}^{n} \sigma^{2}(S i)}{n}}
\end{gathered}
$$




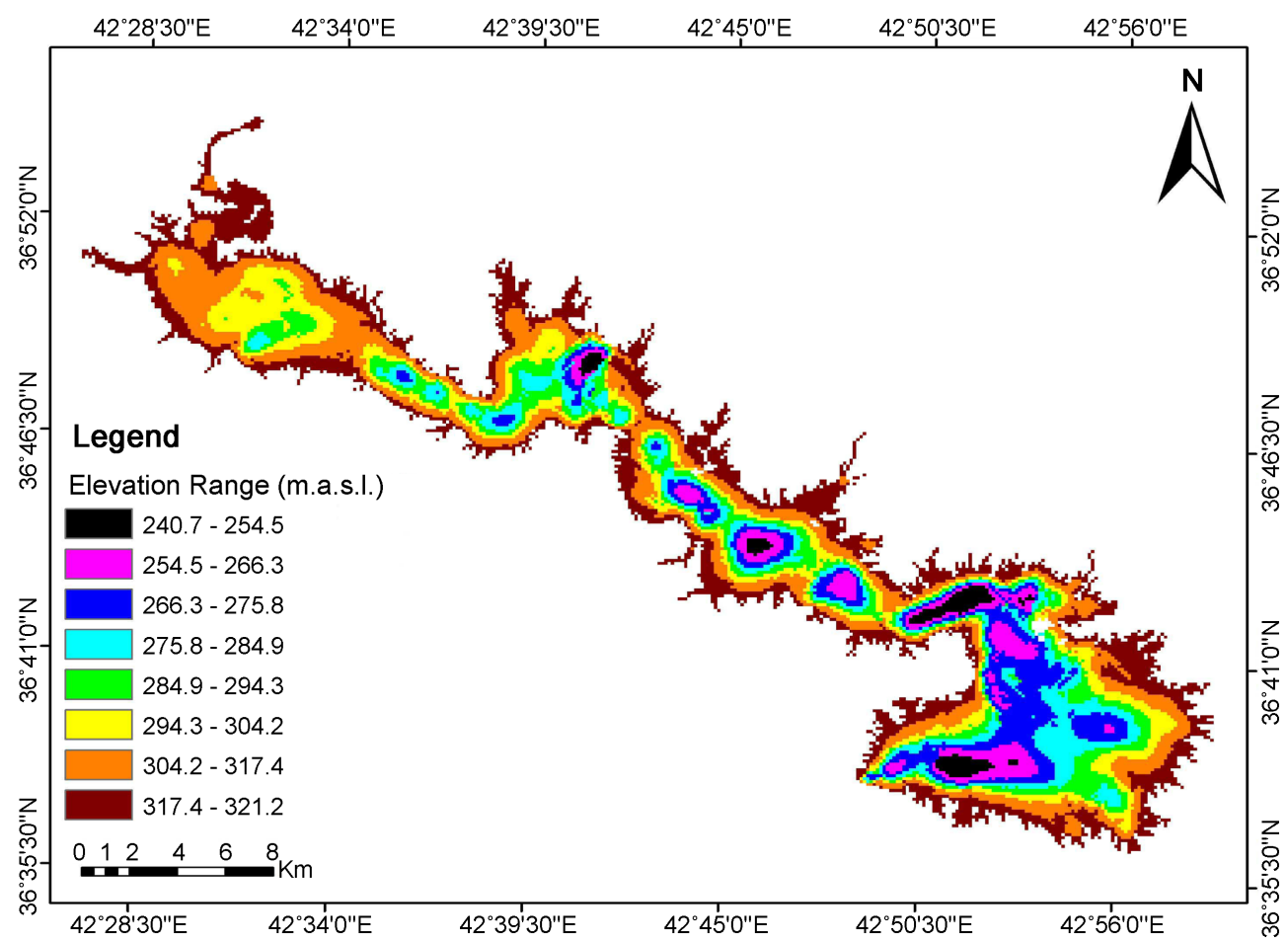

Figure 4. Bathymetric map of Mosul Dam Lake determined using the ordinary kriging interpolation method.

Table 1. Results of root mean square error (RMSE), mean standardized error (MSE), mean error (ME) and average standard error (ASE) determined with the ordinary kriging models for the depth prediction of Mosul Lake.

\begin{tabular}{ccccc}
\hline Model & ME & RMSE & ASE & MSE \\
\hline Stable & 0.12 & 2.74 & 0.64 & 0.01 \\
Circular & 0.18 & 2.73 & 1.12 & 0.03 \\
Expoenetial & 0.21 & 2.80 & 1.15 & 0.04 \\
Spherical & 0.18 & 2.71 & 1.00 & 0.03 \\
Gaussian & 0.06 & 2.75 & 1.38 & 0.09 \\
\hline
\end{tabular}

$$
\mathrm{ME}=\frac{\sum_{i=1}^{n}(Z(S i)-z(S i))}{n}
$$

Most values of the accuracy error indicated that the stable ordinary kriging model is fit to predict the depth of Mosul Lake. Generally, MSE, ASE and ME were lower for the stable model than for the other models (Table 1). Furthermore, the cross-validation scatter plot for predicted and measured depths value showed that the data prediction of this model was better correlated with the measured depth dataset (Figure 5).

After having selected the model, the interpolation process included optimizing the semivariogram model of the dataset. Semivariogram is a graphical form exemplifies calculation of semivariances for different values of distance [20] [33]. A typical example of semivariogram with its component is shown in Figure 6. 

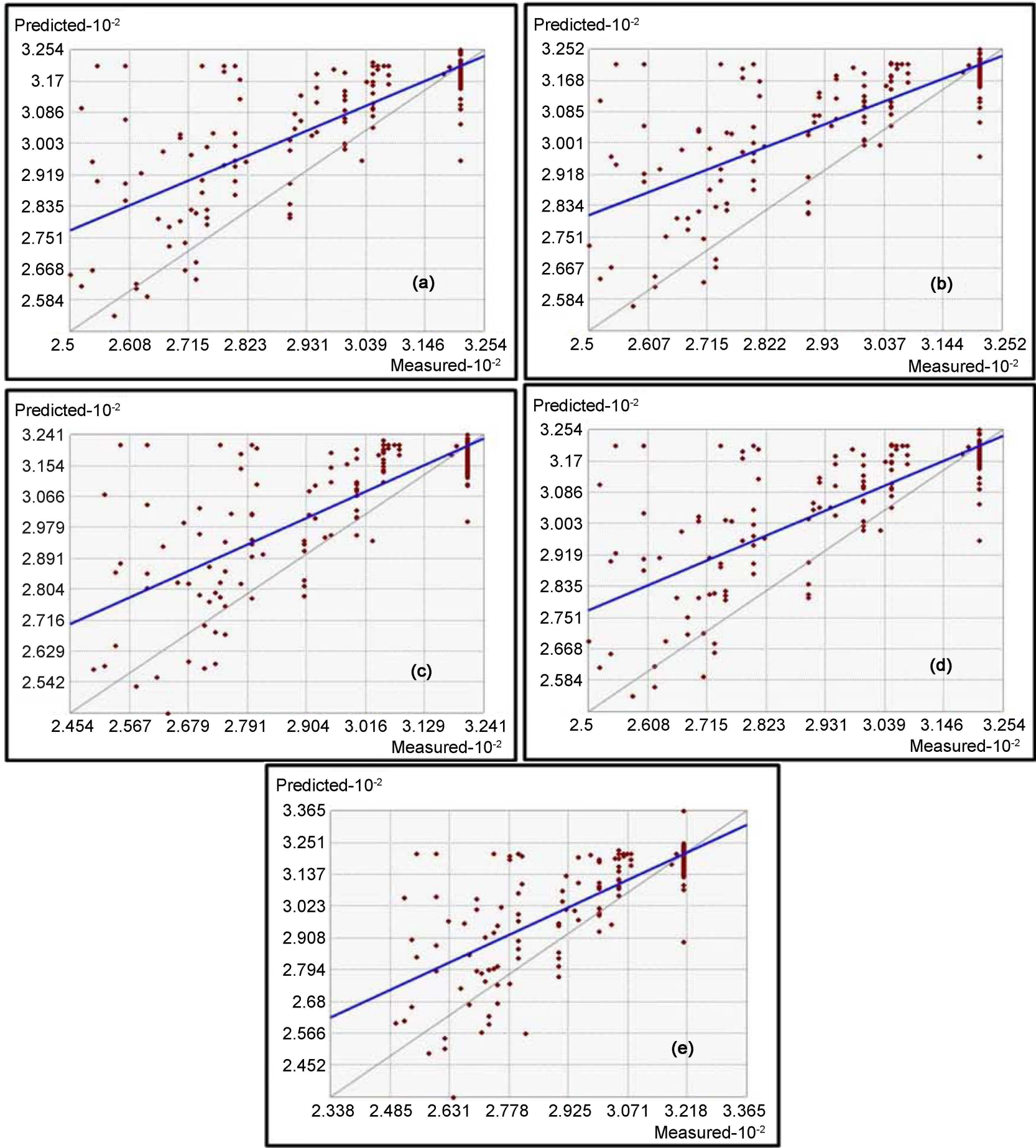

Figure 5. Comparison of the cross-validation (predicted vs. measured depth) of Mosul Lake by ordinary kriging models: (a) circular, (b) exponential, (c) Gaussian, (d) spherical and (e) stable (the blue line is the fitted line and black lines represent a perfect fit $1: 1)$.

The classical semivariogram is calculated by using the following formula [34] [35].

$$
\gamma(h)=\frac{1}{2 n} \sum_{i}^{n}\left[v\left(x_{i}\right)-v\left(x_{i}+h\right)\right]^{2}
$$


where $\gamma$ is the calculated semivariogram of the variable $v$ at the separation distance and direction specified by the "lag" vector $h$, the $x_{i}$ are the data locations and $n$ is the number of data pairs separated by $h$ [34]. Stable model is a powered exponential variogram calculated as [36].

$$
\gamma(h)=c\left\{1-\exp \left[-\left(\frac{h}{r}\right)^{p}\right]\right\}
$$

where $c$ is the total variance or sill parameter, $r$ is the range parameter, and $p$ is the asymptotic power-law exponent [34]. For additional information on other models and semivariogram components can be found in several textbooks on geostatistic [31] [35]. The statistical parameters of the semivariogram which was used for the interpolation of the lake depth values are shown in Table 2.

The relationship between modeled water depths values by ordinary kriging method and observed values for 25 locations are presented in Figure 7. The accuracy water depth showing that the predicated valued are more accurate in shallow water. Also, this figure present in general that the interpolated values at deep region are more than observed, where the heterogeneous terrain with varying slope and curvature impact on the accuracy of modeled values [37]. Generally, the model operates very well with $R^{2}(0.98)$.

\subsection{Volume Calculations}

A three-dimensional TIN model was generated to represent the bottom surface of Mosul Dam Lake (Figure 8). Generally, results of interpolation are used to form the previous figure with $10 \mathrm{~m}$ depth intervals, a minimum depth of zero meters and a maximum depth of $80 \mathrm{~m}$. The elevations of the lake bottom are calculated along the triangulation plane by determining the elevation for each triangular unit. The area and volume were estimated by simple pixels calculation

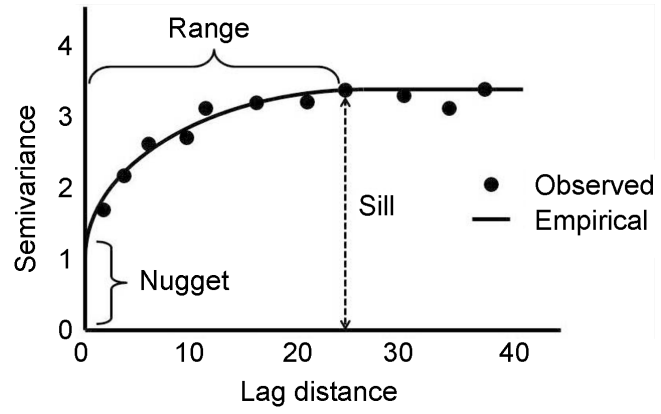

Figure 6. A theoretical example of semivariogram model showing different components [35].

Table 2. Statistical parameters of the semivariogram model for which the ordinary kriging method was used to predict the depth of the lake.

\begin{tabular}{cccccc}
\hline Model & Nugget & $R^{2 *}$ & Range & Lags & Partial Sill \\
\hline Stable & 0.2314 & 0.99 & 2408.1 & 12 & 38.44 \\
\hline${ }^{*} R^{2}$ is the coefficient of determination between predicted and measured depths. & &
\end{tabular}




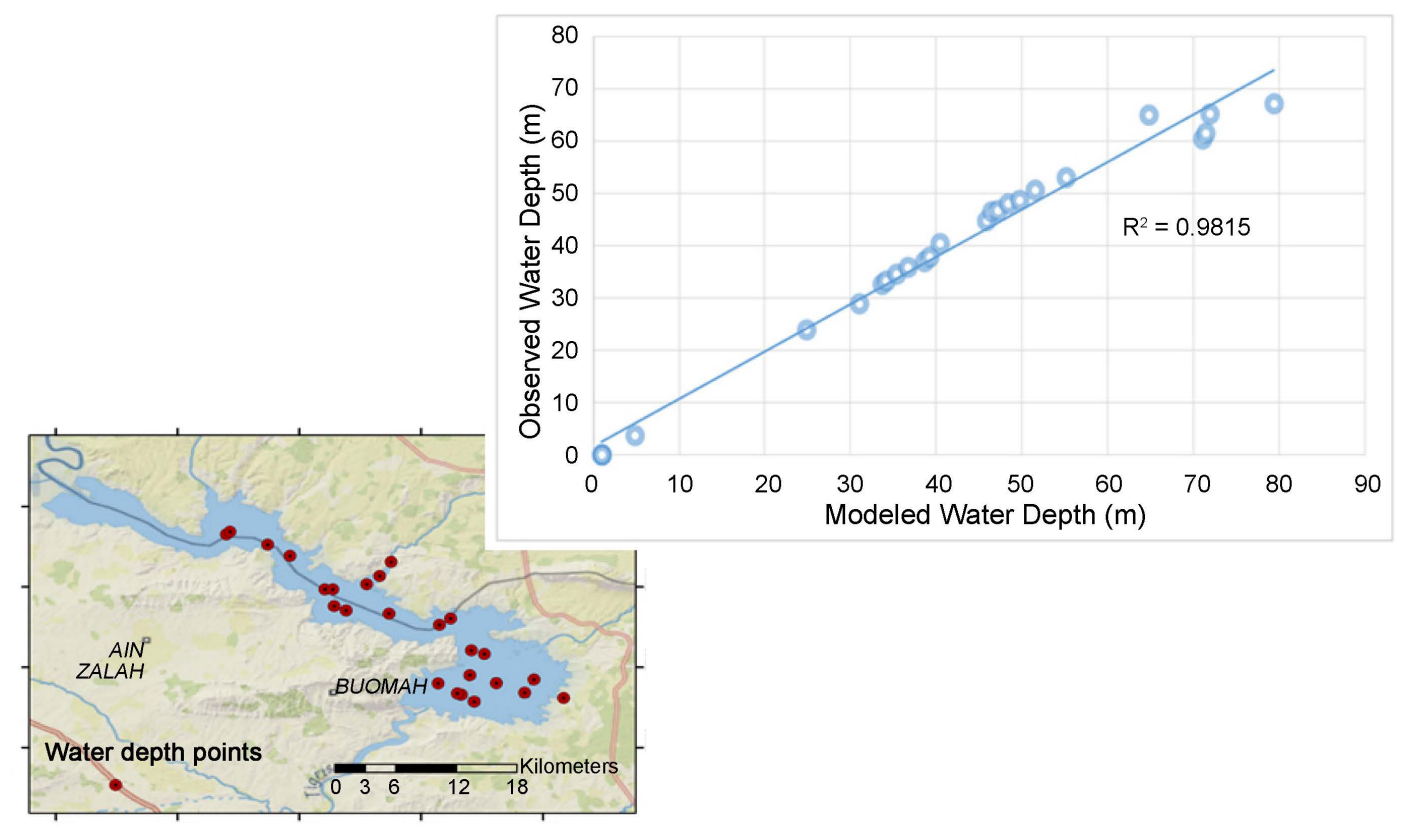

Figure 7. Plots the modeled water depth values against the observed field values with field depth point's map.

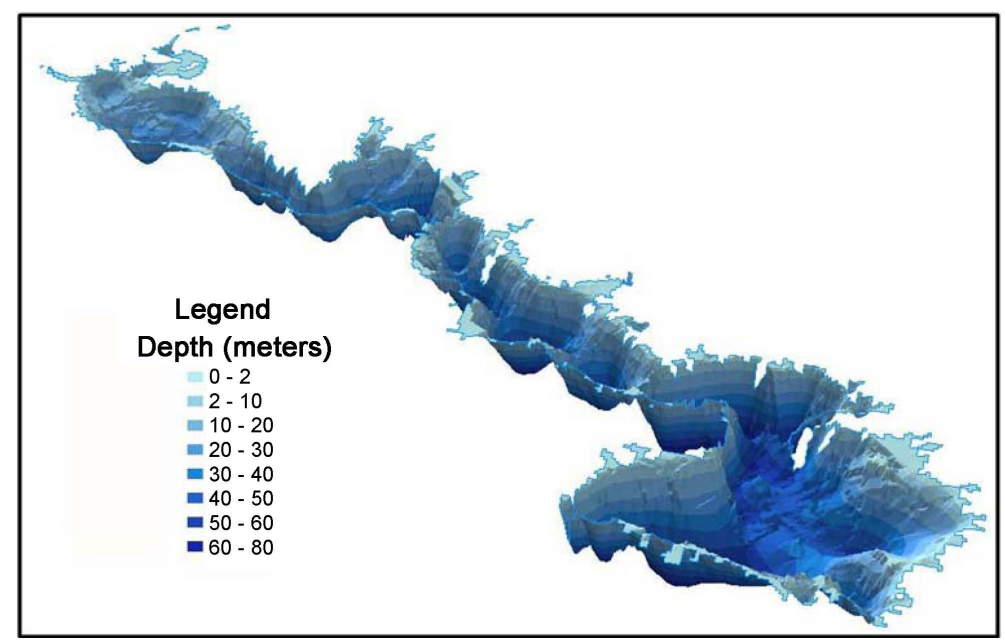

Figure 8. Plots the modeled water depth values against the observed field values with field depth point's map.

for the TIN model. The calculation included 18,275 triangles and $(10,081)$ nodes, and $1 \mathrm{~m}$ elevation tolerance with a 0.99 scale factor. The area projection of the TIN model is Transverse-Mercator with a projected coordinate system WGS-1984, UTM_Zone_38N. Value of area and volume was calculated from the TIN for the entire lake at different elevations (Table 3).

The water storage volumes of Mosul Lake which were calculated by the TIN model were compared with the storage values estimated in 1968 by an IVO operational curve, (Figure 9) for the same elevation (Table 4).

The values of elevation vs. volume were extracted from the operation curve of Mosul Lake by using the Plot Digitizer program. The differences between the 
Table 3. Area/volume from triangulated irregular network model of Mosul bathymetric data collected in 2011.

\begin{tabular}{cccccc}
\hline Elevation (m.a.s.l.) & Area $2 \mathrm{D}\left(\mathrm{km}^{2}\right)$ & Volume $\left(\mathrm{m}^{3}\right)$ & Elevation $(\mathrm{m}$. a.s.l. $)$ & Area $2 \mathrm{D}\left(\mathrm{Km}^{2}\right)$ & Volume $\left(\mathrm{m}^{3}\right)$ \\
\hline 295 & 135.28 & $2.30 \times 10^{9}$ & 309 & 197.16 & $4.63 \times 10^{9}$ \\
297 & 145.64 & $2.58 \times 10^{9}$ & 311 & 205.51 & $5.04 \times 10^{9}$ \\
299 & 154.42 & $2.88 \times 10^{9}$ & 313 & 214.08 & $5.46 \times 10^{9}$ \\
301 & 162.52 & $3.20 \times 10^{9}$ & 315 & 223.13 & $5.89 \times 10^{9}$ \\
303 & 170.71 & $3.53 \times 10^{9}$ & 317 & 232.65 & $6.35 \times 10^{9}$ \\
305 & 179.29 & $3.88 \times 10^{9}$ & 319 & 243.18 & $6.82 \times 10^{9}$ \\
307 & 188.59 & $4.25 \times 10^{9}$ & 321 & 273.80 & $7.33 \times 10^{9}$ \\
\hline
\end{tabular}

Table 4. The differences in storage volume between the TIN model from 2011 and the IVO operation curve from 1968.

\begin{tabular}{cccc}
\hline Elevation (m.a.s.l.) & Volume $_{(\mathrm{IVO})}\left(\mathrm{m}^{3} \times 10^{9}\right)$ & Volume $_{(\mathrm{TIN})}\left(\mathrm{m}^{3} \times 10^{9}\right)$ & Differences $^{\left(\mathrm{m}^{3} \times 10^{9}\right)}$ \\
\hline 321 & 8.14 & 7.33 & 0.81 \\
319 & 7.74 & 6.82 & 0.92 \\
317 & 7.07 & 6.35 & 0.72 \\
315 & 6.31 & 5.89 & 0.42 \\
313 & 5.84 & 5.46 & 0.38 \\
311 & 5.32 & 5.04 & 0.28 \\
309 & 4.90 & 4.63 & 0.27 \\
307 & 4.52 & 4.25 & 0.27 \\
305 & 4.05 & 3.88 & 0.17 \\
303 & 3.65 & 3.53 & 0.12 \\
301 & 3.21 & 3.20 & 0.01 \\
299 & 2.89 & 2.88 & 0.01 \\
297 & 2.58 & 2.58 & 0.00 \\
295 & 2.30 & 2.30 & 0.00 \\
\hline
\end{tabular}

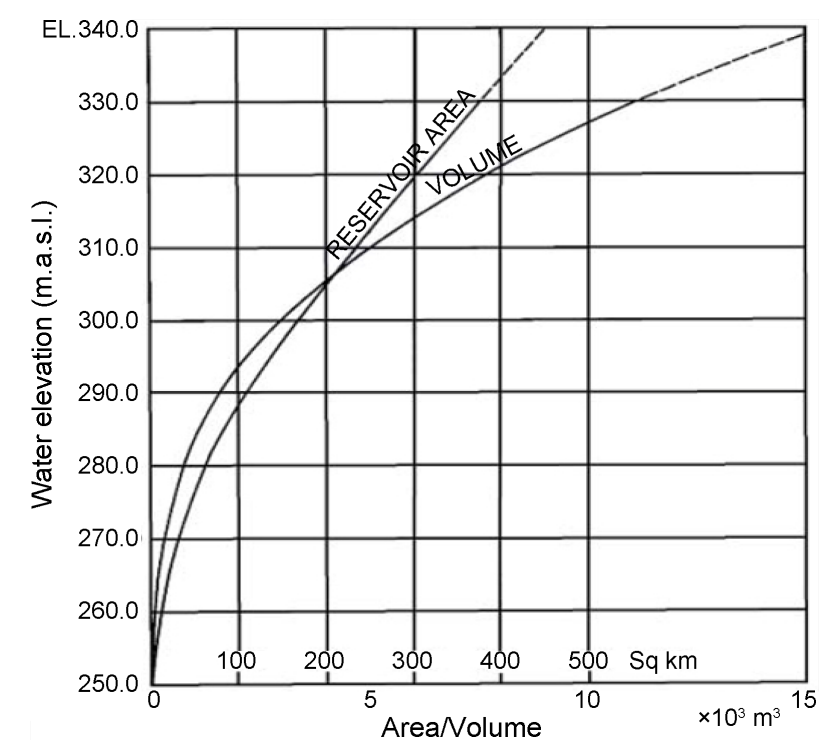

Figure 9. Operating curve of Mosul dam reservoir (IVO 1968) [38]. 
storage volumes of the lake calculated by the TIN model and the IVO operation curve (Table 4) are the result of sedimentation during the lake's operating time. Generally, the sedimentation rate is high in the elevation range of 321 to $303 \mathrm{~m}$ above sea level. Also, the result of the lake volume analysis showed that the change in water volume between March and July 2011 was about $3.8 \times 10^{9} \mathrm{~m}^{3}$.

\section{Conclusion}

The current study explored the ability and certainty of extracting bathymetric map data for the Mosul Dam Lake from a digital elevation model. The study recommended an approach for monitoring volume water storage of this reservoir using remote sensing data and GIS techniques. The methodology tested proved that the ordinary kriging interpolation method is the best model that can be applied to develop bathymetric maps of this lake. Furthermore, the verification performance of this model with observed field data values confirmed the high efficiency for the selected model. This study showed that Mosul Lake has lost about $10 \%$ of its ability to store water up to 2011 . This could be a result of trap efficiency, where sediment from the Tigris River is deposited behind the dam as well as in the valleys around the lake. Also, the Mosul reservoir witnesses high seasonal variation of storage water reaching to $3.08 \times 10^{9} \mathrm{~m}^{3}$ which may lead to fluctuations in environmental conditions. Although, the calculated values of depths in the deeper regions have errors, the proposed model is still highly recommended over the more expensive traditional bathymetric data collection methods such as boat and radar in such a region of the world.

\section{References}

[1] Hollister, J.W., Milstead, W.B. and Urrutia, M.A. (2011) Predicting Maximum Lake Depth from Surrounding Topography. PLoS One, 6, 1-6. https://doi.org/10.1371/journal.pone.0025764

[2] Hydro, L.P. (2011) Bathymetric Study and Assessment of Cedar Lake.

[3] Hakanson, L. (2005) The Importance of Lake Morphometry for the Structure and Function of Lakes. International Review of Hydrobiology, 90, 433-461. https://doi.org/10.1002/iroh.200410775

[4] Britannica, E. (2014) Lake. In: Britannica, E., et al., Eds., Encyclopaedia Britannica, Encyclopædia Britannica Incorporated, Chicago.

[5] Al-Taiee, T.M. and Sulaiman, Y.I. (1990) Preliminary Water Balance of Saddam Dam Lake. Proceedings of the Second Scientific Conference of SDRC, 18-20 March 1990, 121-134.

[6] Iraqi Ministry of Water Resources (2013) Water Resources, Mosul Dam Characteristics. http://www.mowr.gov.iq/?q=node/406

[7] Kelley, J.R., Wakeley, L.D., Broadfoot, S.W., Pearson, M.L., McGrath, C.J., McGill, T.E., Jorgeson, J.D. and Talbot, C.A. (2007) Geologic Setting of Mosul Dam and Its Engineering Implication. Engineer Research and Development Center, Vicksburg.

[8] Saleh, D.K. (2010) Stream Gage Descriptions and Streamflow Statistics for Sites in the Tigris River and Euphrates River Basins, Iraq. U.S. Geological Survey, Reston.

[9] Khattab, M.F.O. and Al-Ani, F.A.M. (2012) Detection Depth of Mosul Reservoir by 
Using Image Processing Techniques. Tikrit Journal of Pure Science, 17, 190-194.

[10] Liu, H. and Jezek, C. (2004) Automated Extraction of Coastline from Satellite Imagery by Integrating Canny Edge Detection and Locally Adaptive Thresholding Methods. International Journal of Remote Sensing, 25, 937-958. https://doi.org/10.1080/0143116031000139890

[11] Dost, R.J.J. and Mannaerts, C.M.M. (2005) Generation of Lake Bathymetry Using Sonar, Satellite Imagery, and GIS. Journal of Clinical Pathology, 53, 803-804.

[12] Khattab, M.F.O. and Merkel, B.J. (2014) Application of Landsat 5 and Landsat 7 Images Data for Water Quality Mapping in Mosul Dam Lake, Northern Iraq. Arabian Journal of Geosciences, 7, 3557-3573. https://doi.org/10.1007/s12517-013-1026-y

[13] National Aeronautics and Space Administration (2006) Landsat 7 Science Data Users Handbook. National Aeronautics and Space Administration, Washington DC.

[14] Pardo-Pascual, J.E., Almonacid-Caballer, J., Ruiz, L.A. and Palomar-Vázquez, J. (2012) Automatic Extraction of Shorelines from Landsat TM and ETM+ MultiTemporal Images with Subpixel Precision. Remote Sensing of Environment, 123, 1 11. https://doi.org/10.1016/j.rse.2012.02.024

[15] Gao, B.C. (1996) NDWI-A Normalized Difference Water Index for Remote Sensing of Vegetation Liquid Water from Space. Remote Sensing of Environment, 58, 257-266. https://doi.org/10.1016/S0034-4257(96)00067-3

[16] McFeeters, S.K. (1996) The Use of the Normalized Difference Water Index (NDWI) in the Delineation of Open Water Features. International Journal of Remote Sensing, 17, 1425-1432. https://doi.org/10.1080/01431169608948714

[17] Bello-Pineda, J. and Hernandez-Stefanoni, J.L. (2007) Comparing the Performance of Two Spatial Interpolation Methods for Creating a Digital Bathymetric Model of the Yucatan Submerged Platform. Pan-American Journal of Aquatic Sciences, 2, 247-254.

[18] Vajsáblová, M. (2013) Variograms and Regression Methods of Their Creation. Scientific Research and Essays, 8, 1998-2007. https://doi.org/10.5897/SRE2013.5656

[19] Aykut, N.O., Akpınar, B. and Aydın, Ö. (2013) Hydrographic Data Modeling Methods for Determining Precise Seafloor Topography. Computers \& Geosciences, 13, 661-669. https://doi.org/10.1007/s10596-013-9347-1

[20] Meilianda, E., Huhn, K., Alfian, D. and Bartholomae, A. (2012) Application of Multivariate Geostatistics to Investigate the Surface Sediment Distribution of the HighEnergy and Shallow Sandy Spiekeroog Shelf at the German Bight, Southern North Sea. Open Journal of Marine Science, 2, 103-118. https://doi.org/10.4236/ojms.2012.24014

[21] Coovaerts, P. (1995) Geostatistics for Natural Resources Evaluation. Oxford University Press, New York.

[22] Kholghi, M. and Hosseini, S.M. (2009) Comparison of Groundwater Level Estimation Using Neuro-Fuzzy and Ordinary Kriging. Environmental Modeling \& Assessment, 14, 729-737. https://doi.org/10.1007/s10666-008-9174-2

[23] Bohling, G. (2005) Kriging. http://people.ku.edu/ gbohling/cpe940

[24] Wackernagel, H. (2003) Multivariate Geostatistics: An Introduction with Application. 3rd Edition, Springer, Paris. https://doi.org/10.1007/978-3-662-05294-5

[25] Popielarczyk, D. and Tomasz, T. (2009) Inventory Taking of the Upper Water Reservoir in Pumped-Storage Power Station in Żydowo Using Classical Land Survey Methods and Integrated Hydroacoustic and Global Navigation Satellite Systems 
(GNSS). Reports on Geodesy, 2, 325-335.

[26] Satellite Imaging Corporation (2013) Digital Elevation Models (DEM). www.satimagingcorp.com

[27] Sawagaki, T., Lamsal, D., Byers, A.C. and Watanabe, T. (2012) Changes in Surface Morphology and Glacial Lake Development of Chamlang South Glacier in the Eastern Nepal Himalaya since 1964. Global Environmental Research, 14, 83-94.

[28] Bater, C.W. and Coops, N.C. (2009) Evaluating Error Associated with Lidar-Derived DEM Interpolation. Computers \& Geosciences, 35, 289-300.

https://doi.org/10.1016/j.cageo.2008.09.001

[29] Shewchuck, J.R. (1996) Triangulation Algorithms and Data Structures. http://www.cs.cmu.edu/ quake/tripaper/triangle2.html

[30] De Wulf, A., Constales, D., Stal, C. and Nuttens, T. (2012) Accuracy Aspects of Processing and Filtering of Multibeam Data: Grid Modeling versus TIN Based Modeling. Proceedings of FIG Working Week 2012, Rome, 6-10 May 2012, 15.

[31] Environmental Systems Research Institute (2003) Using ArcGIS ${ }^{\circledast}$ Geostatistical Analyst. Environmental Systems Research Institute, Redlands.

[32] Altman, D.G. and Martin, B.J. (2005) Standard Deviations and Standard Errors. BMJ, 331, 903. https://doi.org/10.1136/bmj.331.7521.903

[33] Davis, J.C. (1986) Statistical and Data Analysis in Geology. 2nd Edition, John Wiley and Sons, New York, Canada.

[34] Jr, J.W., Ruppel, S.C. and Ward, W.B. (2000) Geostatistical Analysis of Permeability Data and Modeling of Fluid-Flow Effects in Carbonate Outcrops. SPE Reservoir Evaluation \& Engineering, 3, 292-303. https://doi.org/10.2118/65370-PA

[35] Biswas, A. and Si, B.C. (2013) Model Averaging for Semivariogram Model Parameters. InTech, Rijeka, 81-96.

[36] Monestieza, P., Dubrocab, L., Bonninc, E., Durbecc, J.P. and Guinetb, C. (2006) Geostatistical Modelling of Spatial Distribution of Balaenoptera Physalus in the Northwestern Mediterranean Sea from Sparse Count Data and Heterogeneous Observation Efforts. Ecological Modelling, 193, 615-628.

https://doi.org/10.1016/j.ecolmodel.2005.08.042

[37] Christopher, J.A. and Barry, W.E. (2016) Accuracy of Interpolated Bathymetry in Digital Elevation Models. Journal of Coastal Research, 76, 123-133. https://doi.org/10.2112/SI76-011

[38] Imatran Voima Osakeyhtio (IVO) (1968) Hydrological and Reservoir Information. Consulting Engineers, Helsinki, Finland. 
Submit or recommend next manuscript to SCIRP and we will provide best service for you:

Accepting pre-submission inquiries through Email, Facebook, LinkedIn, Twitter, etc. A wide selection of journals (inclusive of 9 subjects, more than 200 journals)

Providing 24-hour high-quality service

User-friendly online submission system

Fair and swift peer-review system

Efficient typesetting and proofreading procedure

Display of the result of downloads and visits, as well as the number of cited articles Maximum dissemination of your research work

Submit your manuscript at: http://papersubmission.scirp.org/

Or contact ars@scirp.org 